\title{
Multifunctional bushing for gas foil bearing - test rig architecture and functionalities
}

\author{
J Roemer',2*, P Zdziebko', A Martowicz'1 \\ 1. AGH University of Science and Technology, Department \\ of Robotics and Mechatronics, al. Mickiewicza 30, 30-059 \\ Krakow, Poland \\ 2. Oslo Met - Oslo Metropolitan University, Postboks 4, St. \\ Olavs Plass, 0130 Oslo, Norway
}

\begin{abstract}
The following content refers to the thermal aspects of Gas Foil Bearing (GFB). The GFBs are the subgroup of journal bearings, for which lubrication is provided by air, instead of 'traditional' lubricants like oil, graces etc. Gas Foil Bearings offer specific features unachievable for traditional bearings. GFB can operate with rotating speed up to several dozens of $\mathrm{krpm}$ in extreme temperature up to hundreds of Celsius degrees. However due to their specific construction, GFBs are prone to specific thermal issues which complicate their design process. Until now, many tools, mainly based on numerical models were developed. Their effectiveness is evaluated based on experimental data. Due to the high complexity of GFB's structure, the temperature measurement is a challenging task and so far, no reliable simple technique was proposed. There is still a need for developing reliable measurement techniques, allowing for precise temperature measurement. This paper presents the novel approach to temperature measurement of the GFBs compliant structure. The unique concept of foil with integrated sensors was presented and described in detail.
\end{abstract}

\section{INTRODUCTION}

The following content refers to the thermal aspects of Gas Foil Bearing (GFB). The GFBs are the subgroup of journal bearings, for which lubrication is provided by air, instead of 'traditional' lubricants like oil, graces etc. [1-2]. The GFBs principle of operation, like in other journal bearings is as follows: the rotating journal creates drag force on the lubricant, which moves between the journal and bushing faces in the form of a thin film. Above a certain rotating speed, the hydrodynamic pressure in the lubricant film is sufficient to overcome the shaft load. From this point, shaft and bearing bushing become fully separated by the lubricant film, which significantly reduces the friction. This principle of operation is the same regardless of the chosen lubricant type. According to the name, GFBs are lubricated by air, usually supplied from the environment. The 'Foil' component in GFBs name regards to the specific construction of this type of bearing [3]. Figure 1 shows the comparison of 'traditional' oil lubricated journal bearing and GFB. The journal bearing consists of journal and bushing, while GFB has also the system of thin foils located between the bushing and journal. The role of foils will be explained later on along with the specific features of the air lubrication. 


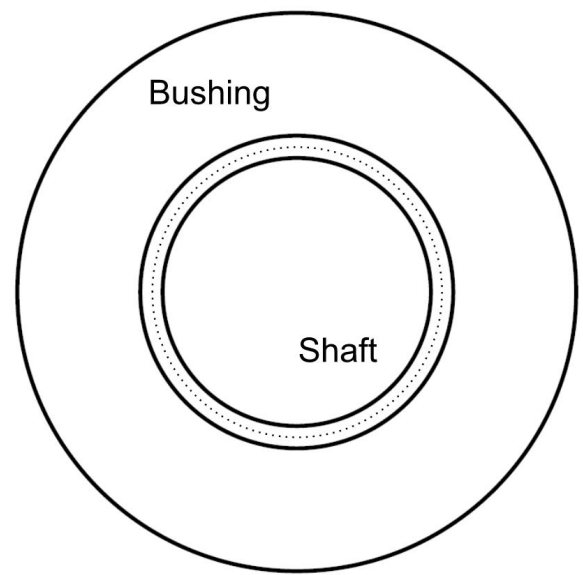

Oil film

(a) Conventional oil lubricated bearing

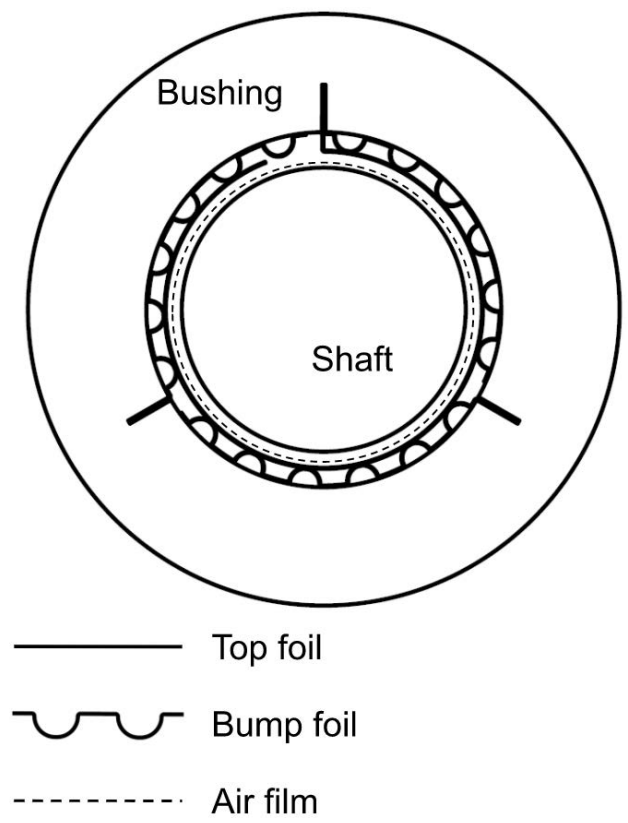

(b) Multilevel solid/gas lubricated air bearing

Fig 1. Schematic representation of systems approaches to bearing lubrication 
Oil lubrication is one of the most common ways for providing long, durable and effective operation of many rotor-type machinery. There are numerous types of oil, each designed for a wide or very narrow spectrum of applications. On the other hand, there is a very interesting alternative for lubricant, which is just air. In specific conditions (rotating speed, load), air can provide not worse lubrication along with very interesting advantages. Air in most applications is free and practically unlimited. Thus the maintenance of GFBs can be reduced to a minimum. Air is (in wide range) immune to temperature which makes it applicable where using regular graces would be impossible due to their degradation hazard. Air is also clean in both chemical and biological meaning. It makes the GFBs a potential candidate for applications where this feature is needed.

Air in comparison with oil or other commonly used graces has significantly lower stiffness. It makes the GFBs suitable for low loaded applications. On the other hand, air lubrication allows the bearing to operate at relatively high rotating speeds. Therefore, GFSs can still handle high power systems as long as the energy is transmitted 'by speed' rather than 'by load'. Low bearing operational load opens the completely new path for GFB's development. As it was mentioned earlier, the construction of GFBs consists of a system of thin foils. The role of the foils is to introduce additional compliance into the system [4-5]. This feature makes the GFBs able to better handle changing operational conditions, improves dynamic parameters of the system and forgives slight misalignment of the shaft. The foils structure consists of a top foil which supports air film, and a set of bump foils responsible for compliance of the structure. The geometry (thickness, number of bumps, shape etc.) of the compliance structure is constantly under development which results in several generations [67] as well as completely new concepts of GFBs [8-11]. Also new manufacturing techniques are under constant investigation [12-13].

Figure 2 shows temperature balance of the working GFB. It has to be noticed that only $8.8 \%$ of the heat is conducted into the bearing bushing [14]. The reason for that lies in the specific construction of the compliant structure. Thin foils have low ability to transfer heat thus its role in overall balance is low [15]. The majority of heat generated inside the bearing is transferred within gas film flow. Heat conduction is an efficient phenomenon and provides good GFB energy management [16-17].

Despite many advantages, GFBs also have specific drawbacks, which significantly reduce their potential. The compliant structure construction is based on several thin foils. Instead of solid bushing, thin foils are sensitive to changing operational conditions. Overall low heat capacity makes the compliant structure very sensitive to thermal excitation. Even relatively low changes in thermal conditions can result in fast temperature increase. As it was mentioned earlier, GFBs are not sensitive to even high temperatures. Air provides sufficient lubrication in a wide range of temperatures. However, it is valid only when proper airflow is provided to the interior of the bearing [19].

Air film creates a thin gap in order of microns between a high-speed rotating shaft and a top foil of a bearing. This clearance has to be sufficient to provide air circulation between the interior of a bearing and the surroundings. Maintaining this clearance is crucial for a proper thermal management of the GFB [20-21]. 


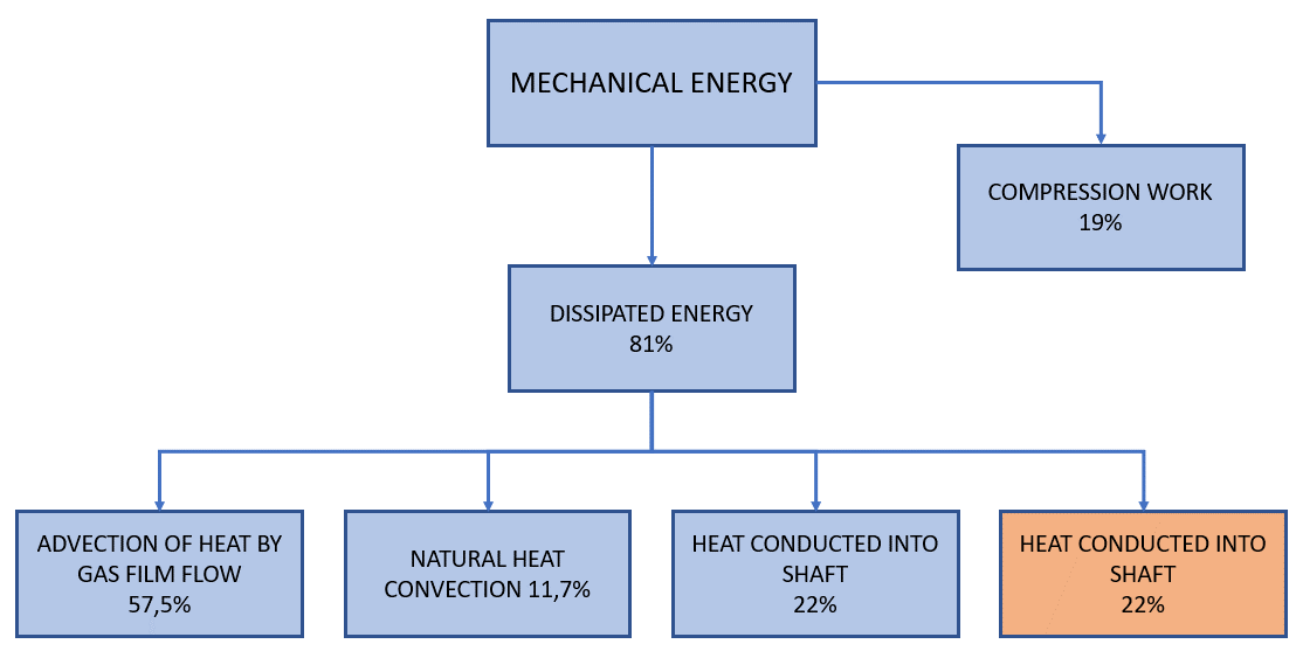

Fig. 2. Total energy balance in GFB [18]

Things get complicated when GFB is exposed to rapidly changing thermal conditions [2223]. Excessive temperature gradient in the foils structure can result in uneven thermal expansion. In some circumstances, foil can wrap in such a manner that reduces the clearance necessary for sufficient fresh air supply. Without fresh air, thermal management of GFB becomes unstable. Rising temperature increases the foil thermal expansion, clearance becomes even more reduced. This could start the chain reaction where bearing malfunction is a matter of minutes or even seconds [24]. The excessive temperature gradient and the chain reaction can occur within relatively low overall temperatures. The lack of preliminary symptoms makes this type of failure very difficult to predict thus dangerous [25].

\section{PROBLEM DEFINITION}

Due to the specific thermal management issues (in high demanding applications) GFBs require more sophisticated temperature monitoring [26]. However simple one point temperature measurement has to be extended by multipoint monitoring of the bearing's top foil. Only this type of measurement can provide information on temperature gradient which is crucial for effective failure prediction. The above observations prompted the authors of this article to propose a new approach based on the concept of a set of temperature sensors (thermocouples) applied directly on the surface of the top foil (on the side of the top foil, which is not in mechanical contact with a rotating shaft). In addition, the proposed concept assumes the use of multiple thermocouples (18 pieces), which according to the adopted assumptions, will allow the identification of the temperature field within the entire top foil. Therefore, the proposed concept requires the design of a foil that is also a sensor. Conducting research using this innovative approach also requires an individual design of all components of the measuring stand and track. In summary, it should be noted that the main application purpose of the innovative measurement methodology with the use of the foil-sensor is to: 
1. Allow to perform temperature measurements directly at the points in the top foil and not indirectly at other bearing components (e.g. bump foil). To the best of the authors' knowledge, it is a new approach on a global scale.

2. Allow to perform the measurement at multiple points of the top foil - this will allow the temperature field to be measured in the entire foil area.

The achievement of these research objectives will constitute a significant research improvement in the context of the state-of-the-art review presented in Section 2. The proposed approach of the implementation of the foil-sensor in the construction of the GFB imposes certain structural and technical requirements on the measuring stand and track. It is necessary to take into account technical aspects related inter alia to the following problems:

1. Measuring the temperature at multiple points of the foil requires many signal cables to be led outside the bearing. This requires that the bearing components are properly designed.

2. Temperature measurements should be made under realistic operating conditions for the GFB. It is necessary to integrate the bearing with the bearing shaft rotating at high speed (> 24'000RPM).

3. For the purpose of testing the measuring track, it is necessary to simulate the heating up of the bearing due to the operation of the highly rotating shaft. This will allow the system to be tested in stationary conditions.

The implementation of these requirements is essential to achieve the set research goals. An important research contribution of the postulated research concept of GFBs is both the innovative top foil, which is at the same time a sensor, and the innovative design of bump foil, bearing shields and its housing, whose shape should enable safe and reliable output of the measurement signals to the signal processing system.

\section{PROBLEM SOLUTION}

The following chapter presents the concept of a measuring path with proposals for specific technical solutions for temperature field measurements using innovative sensor-foils. The concept presented in this work is a development of an idea proposed by the authors in an earlier publication [27]. The approach proposed in this article is that the temperature sensors are directly integrated with the top foil already at the stage of its production. Platinum wires are welded to the surface of the top foil (made of Inconel alloy) - thermocouples are created and the whole top foil becomes a sensor. This allows to eliminate assembly uncertainties that can occur when attaching (by gluing and pressing) commercial sensors. It is a very compact solution that does not significantly affect the parameters of the top foil itself, e.g. its stiffness. Although the solution presented earlier by the authors allowed the temperature inside the bearing to be measured, the solution was susceptible to damage. The issue is to lead the wires from the thermocouples to the signal processing system - cables were tearing off during the 
assembly of the bearing. The decision was made to change the design of the bearing components in order to ensure the reliability of the results by means of a modified method for leading the wires from the thermocouples. This concept is presented in this chapter.

As in the previously presented approach, it was decided to create the thermocouples on top foil by welding platinum wires to the developed top foil on the outside (which is not in mechanical contact with the shaft). The second thermo-electrode for each thermocouple is a section of top foil, which is common for all thermocouples (the so-called lock). The conceptual design of top foil with applied thermocouple wires is presented in Figure 3a.

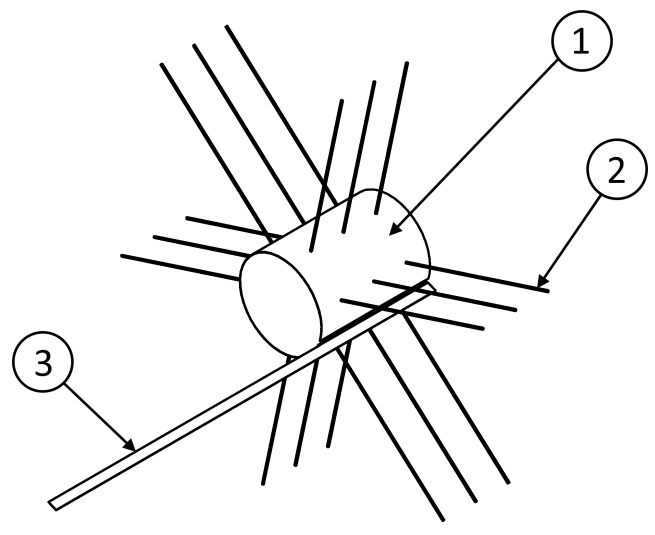

a) 1 - top foil, 2 - platinum electrode (18 pieces in total), 3 - common electrode (Inconel).

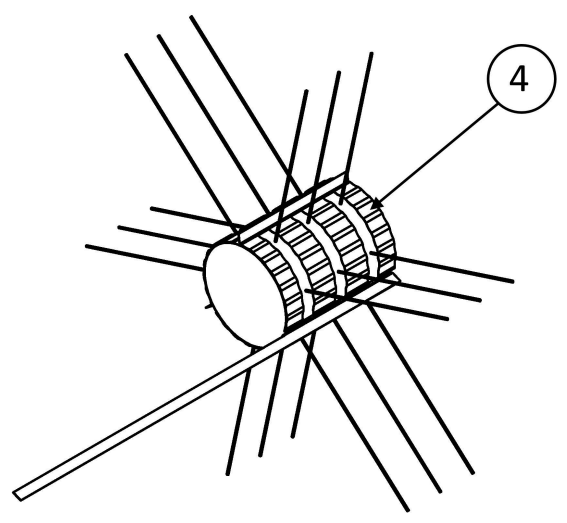

b) 4 - Bump foil.

Fig. 3. Top foil and bump foil with thermocouples. 
In total, 18 measuring points were taken on the surface of the foil. This number is dictated by technical limitations and the desire to install as many temperature sensors as possible. For a single third of the bearing shell, it was possible to install 2 rows of 3 electrodes each. The bearing shell is made of three thirds, so a total of 18 electrodes were installed. As mentioned in the previous chapter, the use of multiple thermocouples requires an appropriate way of leading out signal cables forward to subsequent components of the measuring system. It is therefore necessary to design the individual shape of the bearing shell, bump foil, and bearing housing to meet this requirement. Figure 3b shows a bump foil with designed cut-outs, that allow to lead out electrodes welded to the top foil. However, their main purpose is to ensure the independent operation of the individual strips of the bump foil, which is beneficial in terms of improving the dynamic properties of the GFB.

Likewise, the bearing shell must also be able to lead out these cables, so its design includes cut-outs to lead the cables out. In addition, to enable the assembly of the bearing components, it is proposed that the shell should be divided into three sections and additional flanges on both sides should be used, which will provide stiffness to the shell components (by means of screw connections), while allowing the bump foil, top foil and the shell to be assembled together. In order to guarantee the appropriate assembly tolerances of the bearing shell, the thirds are cut out (by means of EDM) from a single piece of material. The conceptual design of the elements described above is presented on Figure 4.

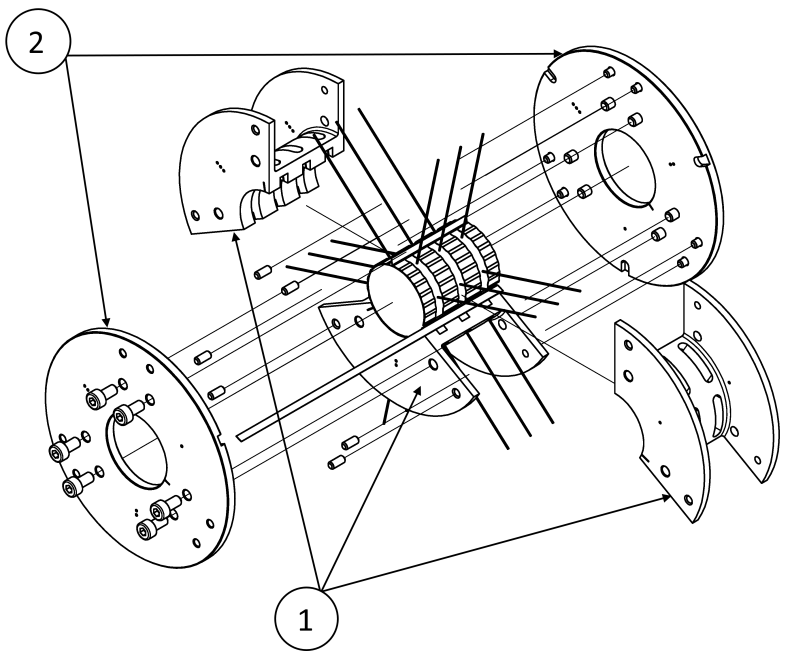

Fig. 4. Exploded view of subassembly: 1 - tricuspid shell, 2 - thrust flange. 
The bearing housing must be able to accommodate the folded tricuspid shell together with the foils (bump and top foils). It has been designed as a two-part foldout and two additional screwed-on thrust rings to immobilize the shell and the foils inside the bearing housing. The housing concept with the rings is shown in Figure 5. The presented design of the GFB components allows to lead-out the measurement signals from the top foil-sensor to the signal processing units.

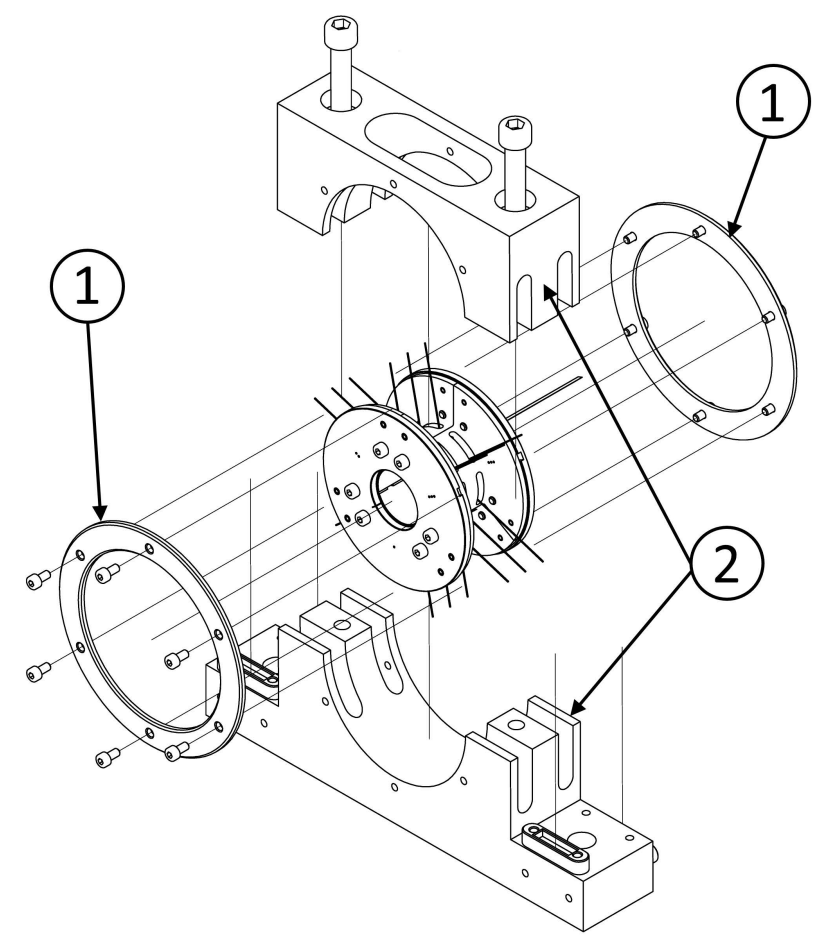

Fig. 5. Exploded view of subassembly: 1 - thrust rings, 2 - bearing housing.

A very important stage in preparation of the sensor-foil is to create thermocouple connections. It is planned to create these joints on the unfolded top foil by welding the platinum wires, the second thermo-electrode will be the lead-out lock of the top foil. The proposed scheme of preparation for the thermocouple joints includes the following stages: 
1. Application of the thermocouple position matrix on the unfolded top foil.

2. Deburring, (preparation) of the surface of the top foil, in the areas of platinum wire welding.

3. Degreasing and dusting the surface.

4. Welding the platinum wire of the thermocouple to the top foil - 18 positions.

The thermocouples position matrix applied on the surface of the top foil is shown in Figure 6. The use of the matrix allows for precise positioning of the thermocouples on the top foil, so that their positions are in accordance with the planned ones. An important stage of surface preparation is deburring, which is a process that requires special precision - the roughness of the outer surface of the top foil must be increased to ensure the best possible welding conditions. At the same time, care must be taken not to deform the top foil as this could result in malfunction of the GFB and its destruction.

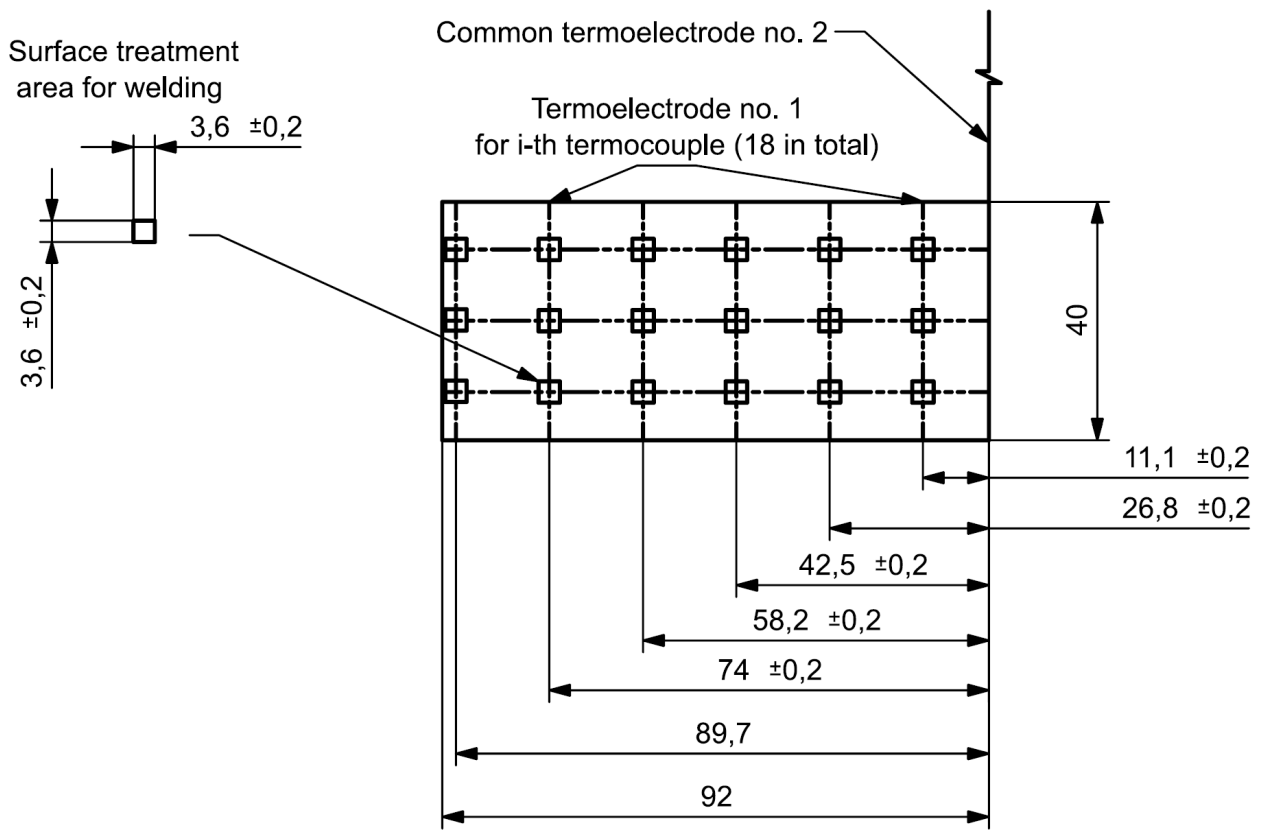

Fig. 6. Top foil with thermocouple position matrix.

Manufacture of a prototype of the foil-sensor is a natural direction for the development of the concept works. Figure 7 depicts the prototype of the foil-sensor in a rolled form on a supporting shaft (which is under the foil, therefore is invisible). The shaft is fixed to the holder and is equipped with supports that prevent the foil from unfolding. The components have been manufactured using 3D printing technology. The process of producing the foil-sensor turned out to be demanding. The difficulties involved welding the thermo-electrodes to the surface of the foil, and to provide sufficient strength of the spot-welds. 
The authors predict the risk of destruction of some spot-welds during the assembly of the GFB components. For this circumstance, inspection holes are designed in the tricuspid shell, which will allow for eventual repair of any thermocouple joints.

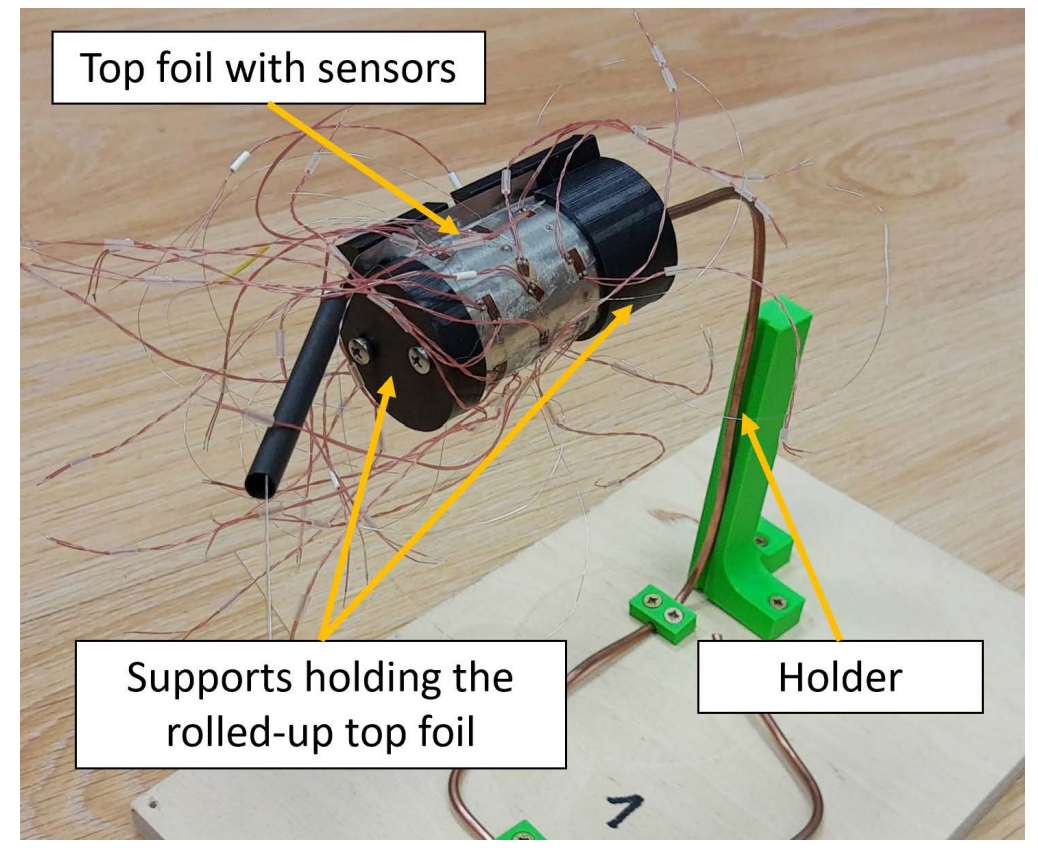

Fig. 7. Prototype of foil-sensor in a holder.

From the initial stage of development of the measurement concept, the elements of the measurement path were defined. It was decided to use a system based on National Instruments components and to develop an application allowing for results visualization and recording based on the LabView environment. The ideal scheme of the measurements is shown on Figure 8 .

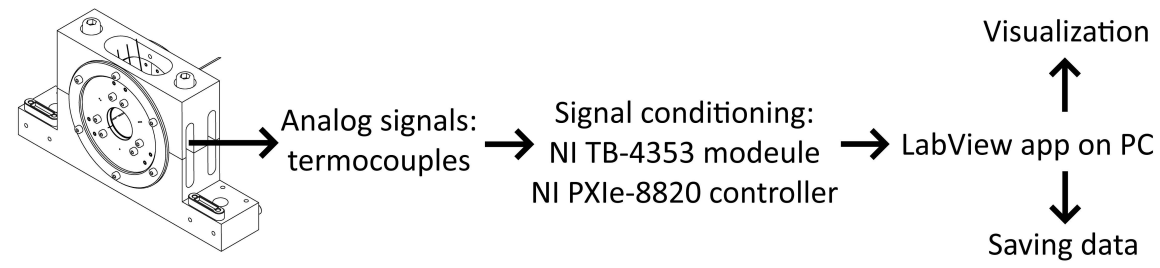

Fig. 8. Scheme of the measurement path. 
Analog signals recorded by the foil-sensors are transmitted to the NI PXIe-8820 controller with use of the NI TB-4353 module. Such selected elements allow for real-time data acquisition on the NI PXIe-8820 controller, where they are cached and then sent in packets to the measuring PC via the Ethernet cable. They are saved to text files on the PC and visualized in the GUI. For the purpose of conducting measurements, an application allows to visualize the results and save data according to requirements. The scheme of its operation is shown in Figure 9. The developed application allows to visualize recorded signals from thermocouples on top foil for all 18 channels simultaneously (Figure 9a). It is also possible to display or hide the relevant channels, which may improve chart clarity or observation of only selected channels. In Addition, the front panel contains an indicator of the highest recorded temperature value and new data acquisition status (green LED). The data storage card (Figure 9b) allows to define the file name and the path for storing the measurement data. Additionally, a text file is created in which the notes entered by the user are saved to better define the measurement conditions. The recording status is indicated by a green LED. Selected system components and a developed application allow for data acquisition, to visualize and save measurement data from the designed sensor-foil.

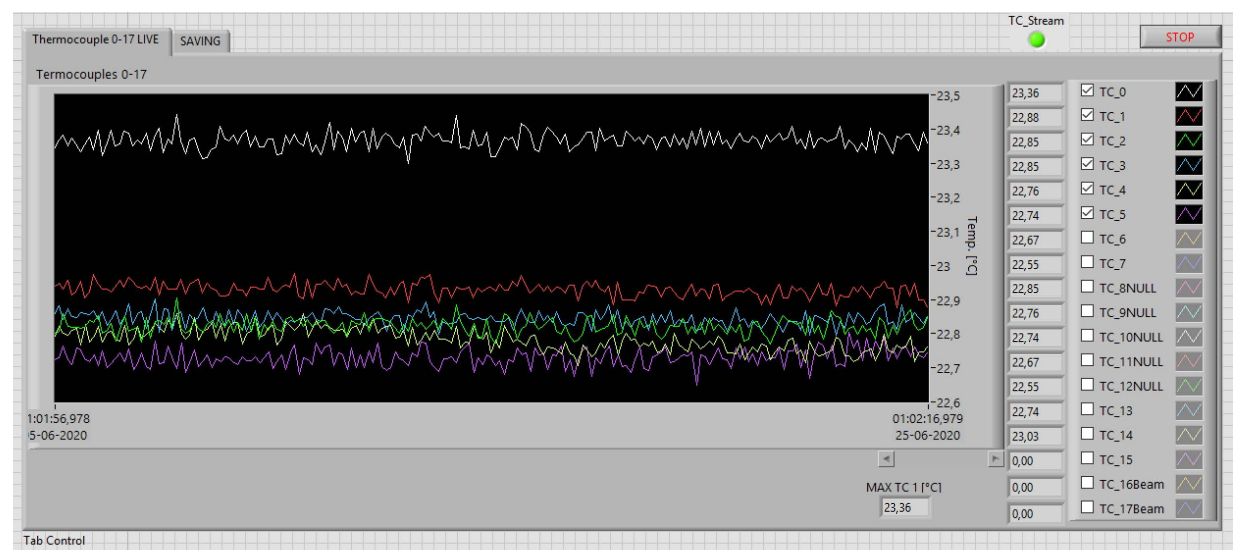

(a) 


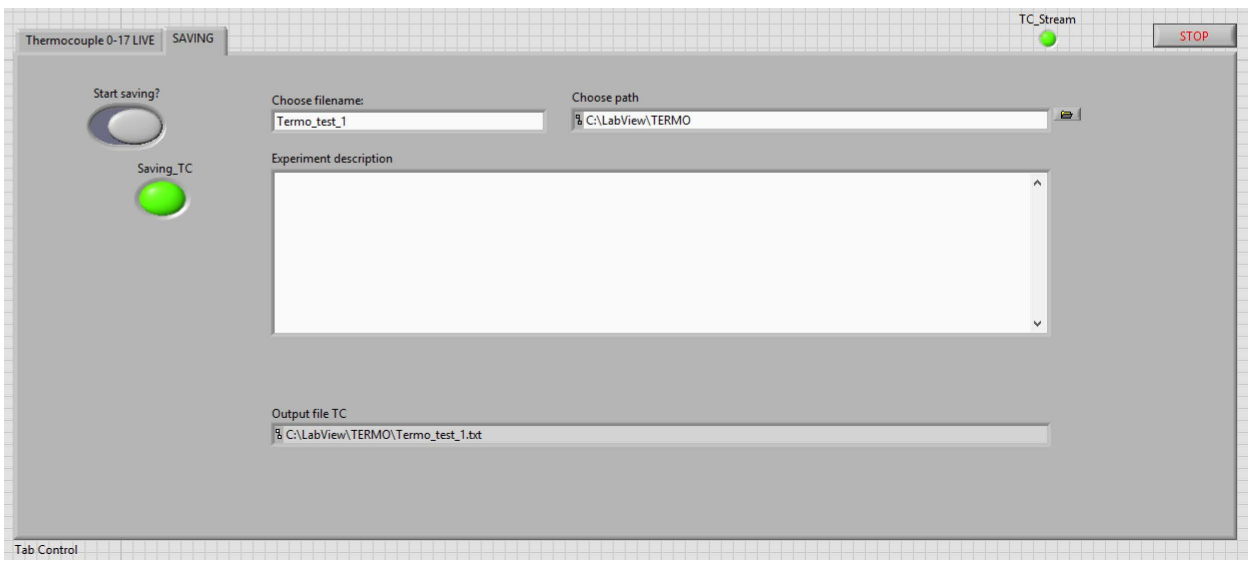

(b)

Fig. 9. Front panel of LabView application: A - data visualization, B - data saving.

\section{SUMMARY AND FINAL REMARKS}

In the presented work, an innovative concept of the foil-sensor for use in GFBs was proposed. The proposed approach allows the temperature to be measured at multiple points in the top foil, which is important - directly on it. This is an important aspect of the innovation of the presented approach. In addition, temperature measurement in many locations allows to determine the distribution of the temperature field within the top foil and analyze the gradient of temperature changes at a later post-processing stage. As part of the work, an innovative design of the top foil was developed and the components of the GFB were designed - the shape of which allows for uninterrupted output of measurement signals from the top foil. As part of the conceptual phase, designs of the individual elements of the GFB were developed, the technology of thermo-electrodes creation was proposed, the components of the measuring system were selected and the application allowing for reading, visualizing and recording the results was developed. As part of further work, it is planned to produce the designed GFB components, apply thermo-electrodes on the top foil and assemble the entire stand and perform the necessary tests under laboratory conditions.

\section{ACKNOWLEDGEMENTS}

The research was funded by National Science Center, Poland (Grant Number OPUS 2017/27/B/ST8/01822 Mechanisms of stability loss in high-speed foil bearings-modeling and experimental validation of thermomechanical couplings).

\section{REFERENCES}

[1] MCAULIFFE, Christopher; DZIORNY, Paul J. Bearing cooling arrangement for air cycle machine. U.S. Patent No 5,113,670, 1992.

[2] SAMANTA, P.; MURMU, N. C.; KHONSARI, M. M. The evolution of foil bearing technology. Tribology International, 2019, 135: 305-323.

[3] SAMANTA, P.; MURMU, N. C.; KHONSARI, M. M. The evolution of foil bearing technology. Tribology International, 2019, 135: 305-323.

[4] GU, Yongpeng; REN, Gexue; ZHOU, Ming. A fully coupled elastohydrodynamic model for static performance analysis of gas foil bearings. Tribology International, 2020, 106297. 
[5] SHALASH, Karim; SCHIFFMANN, Jürg. On the manufacturing of compliant foil bearings. Journal of Manufacturing Processes, 2017, 25: 357-368.

[6] HESHMAT, Hooshang. High load capacity compliant foil hydrodynamic journal bearing. U.S. Patent No 5,902,049, 1999.

[7] AGRAWAL, Giri L. Foil air/gas bearing technology—an overview. In: ASME 1997 international gas turbine and aeroengine congress and exhibition. American Society of Mechanical Engineers Digital Collection, 1997.

[8] LIU, Wanhui, et al. Investigation on the rotordynamic performance of hybrid bump-metal mesh foil bearings rotor system. Mechanical Systems and Signal Processing, 147: 107076.

[9] LAI, Tianwei, et al. Numerical and experimental studies on stability of cryogenic turboexpander with protuberant foil gas bearings. Cryogenics, 2018, 96: 62-74.

[10]ZHANG, Kai, et al. Thermohydrodynamic analysis and thermal management of hybrid bump-metal mesh foil bearings: Experimental tests and theoretical predictions. International Journal of Thermal Sciences, 2018, 127: 91-104.

[11]FENG, Kai, et al. Analysis of novel hybrid bump-metal mesh foil bearings. Tribology International, 2016, 103: 529-539.

[12]SHALASH, Karim; SCHIFFMANN, Jürg. On the manufacturing of compliant foil bearings. Journal of Manufacturing Processes, 2017, 25: 357-368.

[13]HAA, D. N.; XUB, Yanmeng. High Precision Manufacturing for Air Foil Bearings. 2017.

[14]KIM, Tae Ho; SAN ANDRÉS, Luis. Thermohydrodynamic model predictions and performance measurements of bump-type foil bearing for oil-free turboshaft engines in rotorcraft propulsion systems. Journal of tribology, 2010, 132.1.

[15]SALEHI, Mohsen; SWANSON, Erik; HESHMAT, Hooshang. Thermal features of compliant foil bearings—-theory and experiments. J. Trib., 2001, 123.3: 566-571.

[16]SIM, Kyuho; KIM, Tae Ho. Thermohydrodynamic analysis of bump-type gas foil bearings using bump thermal contact and inlet flow mixing models. Tribology international, 2012, 48: 137-148.

[17]LEE, Donghyun; KIM, Daejong. Thermohydrodynamic analysis of bump air foil bearings with detailed thermal model of foil structures and rotor. Journal of Tribology, 2010, 132.2.

[18]Martowicz, Adam; Roemer, Jakub; Lubieniecki, Michał; Żywica, Grzegorz; Bagiński, Paweł. Experimental and numerical study on the thermal control strategy for a gas foil bearing enhanced with thermoelectric modules. Mechanical Systems and Signal Processing, 2020, 138: 106581.

[19]SHRESTHA, Suman K.; KIM, Daejong; CHEOL KIM, Young. Experimental feasibility study of radial injection cooling of three-pad air foil bearings. Journal of Tribology, 2013, 135.4

[20]SAMANTA, P.; KHONSARI, M. M. On the thermoelastic instability of foil bearings. Tribology International, 2018, 121: 10-20.

[21]ŻYWICA, G.; BAGIŃSKI, P.; KICIŃSKI, J. Selected operational Problems of highspeed Rotors supported by Gas Foil Bearings. Technische Mechanik. Scientific Journal for Fundamentals and Applications of Engineering Mechanics, 2017, 37.2-5: 339-346.

[22]SAMANTA, P.; KHONSARI, M. M. On the thermoelastic instability of foil bearings. Tribology International, 2018, 121: 10-20. 
[23]RYU, Keun; SAN ANDRÉS, Luis. On the failure of a gas foil bearing: high temperature operation without cooling flow. Journal of Engineering for Gas Turbines and Power, 2013, 135.11.

[24]RYU, Keun; SAN ANDRÉS, Luis. On the failure of a gas foil bearing: high temperature operation without cooling flow. Journal of Engineering for Gas Turbines and Power, 2013, 135.11.

[25]Roemer, Jakub; Lubieniecki, Michał; Martowicz, Adam. Experimental study on the gas foil bearings air cooling based thermal management method, in: The International Conference of Multiphysics, Beijing, China, 14-15 December, 2017.

[26]KIM, Daejong; ZIMBRU, George. Start-stop characteristics and thermal behavior of a large hybrid airfoil bearing for aero-propulsion applications. Journal of engineering for gas turbines and power, 2012, 134.3.

[27]Lubieniecki, Michał; Roemer, Jakub; Martowicz, Adam; Wojciechowski, Krzysztof; Uhl Tadeusz. A multi-point measurement method for thermal characterization of foil bearings using customized thermocouples. Journal of Electronic Materials, 2016, 45 (3): 14731477. 